\title{
Snftem
}

ber

\section{Arithmetik und Algebra}

alв

\section{Reitfuden für Den danterridgt}

in

\section{höheren Sdulen.}

\author{
\$or
}

\section{Dr. fermann Sidubert,}

Sberlebrer an ber Belehrtenfoule bes gohanneums in Samburg.

\section{Dotsdam, 1885.}

Berlag von Rug. Stein. 


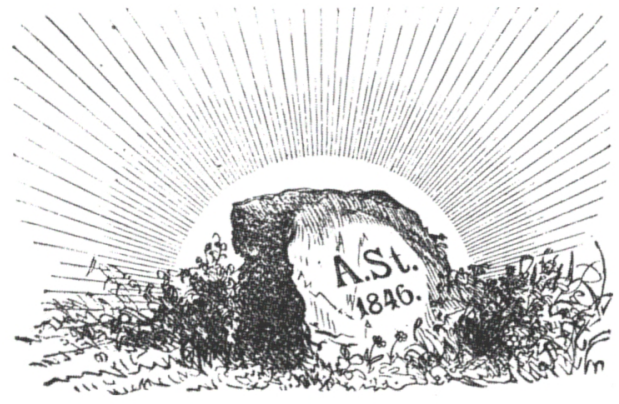

2rue Redte borbebalten. 


\title{
Seinem früberen \&efrer,
}

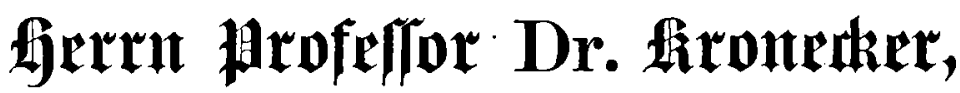

Mitglieb Der Afabentie ber $\mathfrak{B i f f e n j d ) a f t e n ~ z u ~ B e r l i n , ~}$

\author{
als Beichen
}

Der

\section{Daukbarkeit und Werehramg}

gemibmet

vom $\mathfrak{B e r f a f f e r}$. 
